\title{
CORRESPONDENCE
}

\section{Migration in times of COVID-19}

\author{
Mónica Argüeso * [D, José Blanco and Paula Padrón
}

C 2021 Springer-Verlag GmbH Germany, part of Springer Nature

We have read with great interest the recent article by Hraiech et al. [1] published in Intensive Care Medicine where the authors manifest their concern about the critical care illness in recently arrived migrants, the unknown incidence, the therapeutic challenges, and the outcomes of this distinctive patients. They mentioned the "migrant crisis" is probably among the most difficult challenges faced by Western countries since the beginning of the twenty-first century.

As a considerable number of these critical ill migrants are being admitted to our intensive care unit (ICU), several statements can be made regarding this comments. In 2020 , almost 17,000 migrants have reached the coasts of the Canary Islands, six times more than the year before. People fleeing their home in Africa arrive to the Canary Islands after embarking on a long journey during which for many days they are exposed to extreme climatic conditions, violence, pulmonary toxic substances, hunger and thirst [2-4].

As a consequence, the migrants arrive in very poor condition and some of them critically ill [5]. Since October of 2020, many critically ill migrants have been admitted to the ICU, the workload has increased considerably since their arrival was not expected and many of them arrive at the same time requiring critical care support. Similar clinical conditions with a different degree of severity were present in all migrants who were admitted to the Intensive Care Medicine Department: hypothermia, hypernatremia, alteration of the level of consciousness, severe dehydration, hypovolemic shock, hypoxemia and multiorgan failure. The Osborn J waves were found on the electrocardiogram in most of these patients due to severe hypothermia (Fig. 1). Some of them arrived dead or passed away in the first hours after their arrival despite

\footnotetext{
*Correspondence: arguesomoni@yahoo.es

Intensive Care Medicine, Complejo Hospitalario Universitario Insular-

Materno Infantil, Avenida Marítima del sur s/n, Las Palmas de Gran
}

Canaria, 35016 Las Palmas, Spain the resuscitation maneuvers. Some of the migrants had coronavirus disease 2019 (COVID-19), so all of them required strict isolation due to the close contact on the small boat. It is important to be cautious with the presence of infectious diseases (human immunodeficiency virus, chronic hepatitis B infection) and tropical infections.

The critically ill migrants required controlled warming, a large amount of intravenous fluids, close hydroelectrolyte monitorization, mechanical ventilation and high doses of catecholamines. The deadly triad (hypothermia, coagulopathy and acidosis) must be prevented or treated. The skin wounds have to be healed and disinfected because they are the gateway for bacteria and microorganisms that inhabit salt water and cause severe infections, even worse in combination with the poor hygiene conditions, overcrowding and malnutrition. None of the migrants presented severe pneumonia due to COVID-19.

We are really concerned about the future of migration. More studies are needed to evaluate issues such as the incidence of critical care illness in recently arrived migrants, the therapeutic challenges and the expected outcomes $[2,4,5]$. Little information can be provided by us because our case series are small. Studies are needed to better define the specific needs of migrants who become critically ill.

In the current pandemic situation, the already overloaded ICUs in the Canary Islands have been submitted to an increased stress due to the arrival of waves of boats with migrants in critical conditions, compromising the health care services. The situation is such that more critical migrants than COVID-19 patients have been admitted to the ICU during a week. The complexity in the management of these patients is greater given the necessary isolation measures for COVID-19. Migration is not the pandemic, but it is an endemic problem of our civilization. 


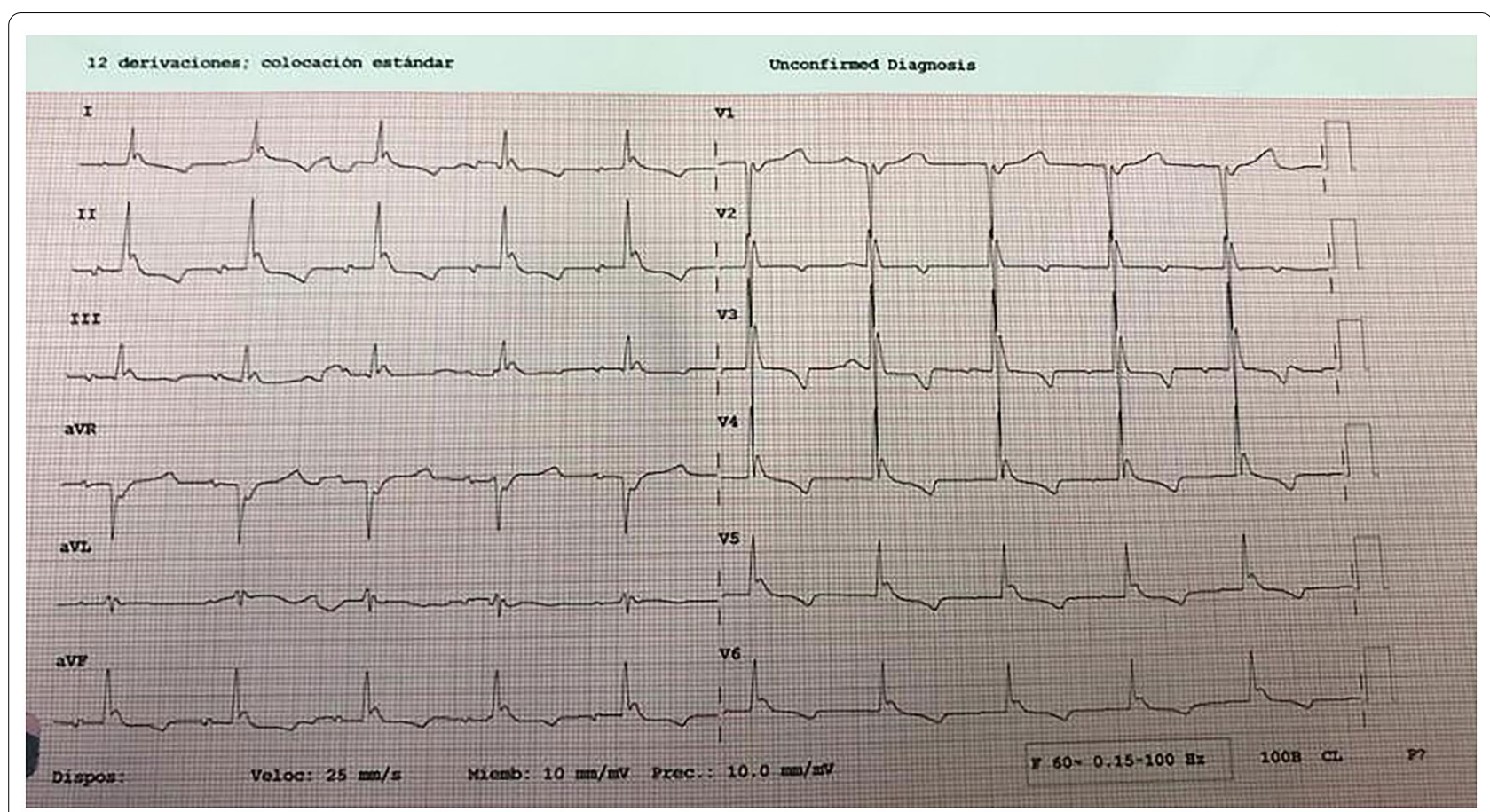

Fig. 1 J wave or Osborn wave found on the ECG of a migrant in the setting of hipothermia. This ECG shows a positive deflection at the J point (negative in $\mathrm{VVR}$ and $\mathrm{V} 1$ ) with a dome or hump configuration most frequently termed a J wave or Osborn wave

\section{Author contributions}

All the authors have contributed equally to the conception, drafting, and final editing of this manuscript.

\section{Declarations}

\section{Conflicts of interest}

The authors declare that they have no conflicts to report.

\section{Publisher's Note}

Springer Nature remains neutral with regard to jurisdictional claims in published maps and institutional affiliations.

\section{Accepted: 27 April 2021}

Published online: 18 May 2021

\section{References}

1. Hraiech S, Papazian L, Azoulay E (2021) Migrants in the intensive care unit: time to show we care. Intensive Care Med 47:473-475. https://doi.org/10. 1007/s00134-020-06318-6
2. Santana L, Rodríguez González F, Villanueva A, Sánchez Palacios M (2007) Rabdomiolisis por hipotermia en el paciente inmigrante ilegal que llega en patera. Nefrología 27(3):394

3. Ponce-Blandón JA, Mérida-Martín T, Jiménez-Lasserrotte MDM, JiménezPicón N, Macías-Seda J, Lomas-Campos MLM (2020) Analysis of prehospital care of migrants who arrive intermittently at the coasts of Southern Spain. Int J Environ Res Public Health 17(6):1964

4. Pasta L, Mesa Suero LA, Filippazzo MG, Farinella EM, Gargano C, Serravalle D et al (2020) The health problems at the landing of the migrants in Lampedusa from 2011 to June 2019: analysis of the data and revision of the literature. J Int Migr Integr 21(4):1295-1308

5. Tsiodras S (2016) Irregular migrants: a critical care or a public health emergency. Intensive Care Med 42(2):252-255 